\title{
Summary of Integrated Design Environment
}

\author{
Chunsheng $\mathrm{Hu}^{1, *}$, Chengdong $\mathrm{Xu}^{2}$ and Xiaobo $\mathrm{Cao}^{3}$ \\ ${ }^{1}$ School of Mechanical Engineering, Ningxia University, Yinchuan, Ningxia, China \\ ${ }^{2}$ School of Aerospace Engineering, Beijing Institute of Technology, Beijing, China \\ ${ }^{3}$ Beijing Mechanical \& Electrical Overall Design Dept., Beijing, China \\ ${ }^{*}$ Corresponding author
}

\begin{abstract}
As one solution to complex product design, the integrated design environment has experienced several decades of development with great changes. This paper reviews the emergence, development history and future trend of integrated design environment. Firstly, the concept and connotation of design are analyzed, and then from the development of design behavior and the development of computer aided design, the inevitability and development history of integrated design environment are elaborated. Secondly, the background and characteristic of different kinds of integrated design environment were analyzed and elaborated. Finally, based on the trend analysis of the integrated design environment, future research direction and goals are proposed. Through this review, basic materials and direction for the related academic research can be provided.
\end{abstract}

Keyword- review; integrated design; complex product design; collaborative design

\section{INTRODUCTION}

As one typical solution for complex product design, the IDE (Integrated Design Environment) builds a unified product development environment, in which relatively independent design modules and design tools are integrated, for practical engineering problems. By this way, variety of design resources are organized via specific design processes to achieve rapid design for complex product [1].

IDE has always been a research spot in the past few decades, and it has solved many problems in different stages [2-7]. With the further complexity increase of modern complex products and emergence of new technologies, the IDE is facing with unprecedented challenges and opportunities.

This paper will summarize the IDE from four aspects. For the IDE is mainly used in fields of aerospace and weapon industry, the following contents will take these fields as line.

\section{CONCEPT OF DESIGN}

IDE is built for problems in product's design stage, and the concept of design is changing all the time. So firstly, the basic concept of design will be elaborated to figure out the object which IDE is aiming at.

The word "design" in different areas have different understandings, generally there are narrow understandings and broad understandings. In the field of industrial product design, several typical narrow understandings are listed as follows.

- Within the conceptual category of digital solid modeling, design stands for a process in which mathematical expressions of the shapes and attributes to objects are confirmed and displayed in form of visual models [8].

- Within the conceptual category of digital design, design stands for a process in which design documents are got from solid modeling, analysis and optimization based on computer hardware and software [9].

- Within the conceptual category of Virtual Prototype, design stands for a process in which multidisciplinary models are integrated to build a virtual prototype for the simulation, analysis and optimization of design plans $[10,11]$.

From the above three typical understandings as we can see, the concept of design has expanded. From the broad point of view, the design stands for a process in which products are got based on the organization and utilization of all kinds of resources include hardware, software, tools, commercial software, multidisciplinary models, knowledge, experience, product data, manufacturing equipment [12].

In general, design is a process in which uncertainty is gradually decreased, or in other words, design is a process in which all product parameters are confirmed gradually. In this process, engineers create a scheme based on known information and collect more information to improve the scheme for following stages. IDE was created to solve various problems of the design process, and it is closely related to the development of design.

\section{APPEARANCE AND DEVELOPMENT OF IDE}

The emergence of IDE is a product of the development of design behavior to a certain degree. On one hand, the increase of design behavior's complexity prompted its emergence, on the other hand, the computer aided design technologies accelerate its progress.

\section{A. From the Development of Design Behavior}

Early design behaviors occur in fixed small groups which have relatively fixed personnel structures and knowledge structures. Some characteristics can be found in this mode.

- Relatively fixed personnel structure is easy to form more and more mature design patterns which can guarantee positive fluctuation to ensure the quality of design. 
- A few people that gain more design knowledge can greatly affect these design patterns, which causes the design quality is more sensitive to changes of these people.

- Increase of product functions will inevitably lead to increase of complexity, the fixed knowledge structure makes it is hard to deal with this kind of situation for a group.

- The inheritance of design knowledge is difficult for the design knowledge is stored in people's brains.

Under these situations, to obtain higher efficiency, lower cost, shorter development cycle and faster response speed, studies are carried out from different angles.

The first one characteristic prompts the emergence of process modeling, process management and process optimization. The BPM (Business Process Management) and WF (Work Flow) are two typical cases. They are developed independently by different organizations, and they have some something in common, while the WF focuses more on business process modeling at upstream part of the entire life cycle and the BPMN focuses more on business process management and driven at downstream part of the entire life cycle [13-15].

The second characteristic and the third characteristic facilitate the emergence of collaboration between different groups and enterprises. CSCW (Computer-Supported Cooperative Work) and DCD (Distributed and Collaborative Design) are two typical cases. The CSCW tries to provide a WYSIWIS (What You See Is What I See) collaborative work environment for members distributed in space and time $[16,17]$. The DCD tries more to achieve integration of heterogeneous design tools and data $[18,19]$. They have many things in common while the CSCW focuses more on a common environment and the DCD focuses more on compatibility and interaction of different design environments.

The fourth characteristic prompts the emergence of some other technologies, like Database, PDM (Product Data Management) [20,21], PLM (Product Lifecycle Management) [22], KM (Knowledge Management) [23], etc.

IDE is one outcome supported by these technologies, it is closer to the concept of common environment in CSCW, but it employs more technologies like the process management, product data management, knowledge management and distributed collaborative.

Strictly speaking, IDE is not a clear defined concept, it is a general designation for a sort of solutions, in which certain kinds of resources are integrated to be shared and used by people in certain scope. The certain property of different solutions is the "unified definition, integration, sharing and reusing” of design resources.

\section{B. From the Development of Computer-Aided Design}

The development of IDE is mainly based on the development of computer technologies, and it can be illustrated from the angle of the computer-aided design development. Computer aided design has experienced about four stages from 1960s [24].

The first stage from 1960s to 1980s takes the development and application of numerical algorithm programs as main feature. In this stage, design theory, method and numerical algorithm are programed into some small specific programs which can help to reduce human works [25-29]. However, the usage scope of these programs is limited within specific groups and these programs offer very limited functionality for single purposes, furthermore, these programs cannot communicate with each other because of lacking of standard interfaces.

The second stage from 1980s to 1990s takes the development of multifunctional platforms as main feature. In this stage, much computer-aided software includes CAD (Computer Aided Design)/CAE (Computer Aided Engineering) /CAM (Computer Aided Manufacturing) programs are developed [30-45]. Usage scope of these programs is expanded to entire industries because these programs break the limitation of functionality and become more and more universal. Furthermore, standard file interaction specifications as IGES (Initial Graphics Exchange Specification) [46] and STEP (Standard for the Exchange of Product Model Data) [47] are proposed to regulate the data interchange across different programs. However, these programs create isolated islands of information because most of them are deployed on singe PC without the power to communicate with other programs via internet.

The third stage from 1990s to 2010s takes the integration, distribution and collaboration of different design tools as main feature [48-60]. On one hand, a lot of design programs greatly expand their functions based on improvement of existing functions, on other hand, design data produced by these programs can be well organized by PLM, PDM or other platforms. Moreover, standard-formed design data can be transmitted automatically via intranet or internet under control of PLD, PDM or other platforms, and the whole design process is under unprecedented control while design knowledge can be stored and reused. The collaborative design [61], the concurrent engineering [62], the manufacturing grid [63], the multidisciplinary design optimization [64] and the virtual prototyping [65] of complex product design get rapid development in this stage. However, the application scope of mature design resources which include software, hardware, design knowledge, design experience and human resources is still limited in specific organization.

The fourth stage from 2010s to nowadays takes the intelligent and service-oriented as main feature. The SOA (Service Oriented Architecture) [66], the CC (Cloud Computing) [67] and the IoT (Internet of Thing) [68] provide remote implementation of software/hardware functions, which brings possibility to utilize remote design module services via internet, and it may achieve a bright future in which worldwide design resources could be collaborated to accomplish one design task.

IDE emphasizes different problems mainly appears in the second and third stage, and its functions are evolving and changing all the time. There are three different categories of 
IDE in brief, the first one is collaboration-oriented, the second one is data-management-oriented and the third one is resources-management-oriented. They will be elaborated as follows.

\section{ClassificAtion OF IDE}

\section{A. Collaboration-Oriented IDE}

There are three kinds of IDE in this category. The first one takes collaboration between CAx software as its main concern, the second one takes collaboration between systems or subsystems of VP (Virtual Prototyping) as its main concern, and the third one takes collaboration between multidisciplinary simulation models of MDO (Multidisciplinary Design Optimization) as its main concern.

\section{1) IDE for collaboration of $C A x$}

This kind of IDE firstly focuses on design data interaction and design data sharing between CAD and CAE software, so elements be integrated in this kind of IDE are CAD or CAE model data files. Its role is to break the barrier between all kinds of CAD/CAE software, to accomplish seamless conversion of CAD and CAE model data files, to achieve a "3D geometric modeling-mesh generation-simulation and analysis” kind of design mode.

This kind of IDE mainly appeared in the 1980s and 1990s when the compatibility between CAD and CAE software is not good. Then, this kind of IDE expanded to the seamless integration among CAD/CAE/CAM software. This kind of IDE once worked as a bridge to connect CAx software developed by different organization, but it is not universal because it is designed to accomplish specific design tasks. Moreover, with the development of data interchange standards and the expansion of software functions, this kind of IDE loses its meaning.

\section{2) IDE for collaboration of VP}

This kind of IDE is built based on the concept of Virtual Prototype which is used to design, optimize, validate, and visualize their products digitally and evaluate different design concepts before incurring the cost of physical prototypes. So, elements be integrated in this kind of IDE are subsystem simulation models.

This kind of IDE's role is to utilize design knowledge from dynamics, materials science, mechanics, optimization theory, simulation, control theory and systems engineering to construct subsystem simulation models for physical prototypes, and then test and evaluate the design plan to verify various characteristics of complex products under real conditions. Till now, this kind of IDE is still undergoing development.

\section{3) IDE for collaboration of $M D O$}

This kind of IDE is built based on MDO theory and method, and it is usually used for complex system design optimization. It is aiming to avoid local optimal solutions and find global optimal solutions by using coupling multidisciplinary design models. So, elements be integrated in this kind of IDE are multidisciplinary design models.
ModelCenter is a typical universal MDO-IDE and it is usually used as a secondary development platform to customize IDE for specific design tasks [69]. Elements can be integrated include user created tools, legacy FORTRAN/C++ programs, spreadsheets, mathematical models, databases, as well as CAD and CAE models. Till now, this kind of IDE is still undergoing development.

\section{B. Data-Management-Oriented IDE}

This kind of IDE takes the management of design data produced in the design process as main purpose, generally, it takes PDM or PLM as platform to organize and transport design data.

This kind of IDE is the most basic and the most important method to accomplish distributed collaborative design. It maintains a consistent design environment for distributed designers and provides standardized interfaces for external applications. Powerful digital design abilities and product data management abilities are key characteristics of this kind of IDE. CATIA is the most successful tool of this kind [70].

\section{Resource-Management-Oriented IDE}

This kind of IDE takes the organization and management of design resources as main purpose. All things utilized in the design propose are supposed to be design resources include hardware, software, algorithm, knowledge, human resources, manufacturing equipment, etc. So, elements be integrated in this kind of IDE are various kinds of design resources.

This kind of IDE tries to make rational plans for design tasks by organization and calling all sorts of design resources. Manufacturing Grid and Cloud Manufacturing [71] are implementations of this kind of IDE in the manufacturing stage. The SOA, CC and IoT provide powerful support for these IDEs.

Simple classification of IDE is carried out above, although these IDEs have different concerns, they have one same core idea: to achieve accessible sharing and using of distributed various design resources. Next part will illustrate the development trend of IDE in future.

\section{FUTURE TREND OF IDE}

Throughout the development of IDE, it can be seen that:

a) The connotation of design behavior is greatly expanded. Now the design is no longer a simple refers to the drawing for products, but a set of stages include modeling, simulation, analysis, manufacturing and sale.

b) The definition of design resources is greatly expanded too. Now design resources cover a range from the digital drawing to various elements involved in the design process.

c) The integration in IDE has changed a lot. It has developed from the integration of software-software, data-data, software-data, model-model and data-model to a grand integration of software-data-model-hardware.

d) The sharing and using scope of various design resources is greatly expanded from small groups to the whole world. 
From these trends, a future IDE will take "sharing and using of distributed design resources" as main concern, and the design resources will include all things involved in design processes. By this IDE, an ideal design pattern in which worldwide design resources could be collaborated to accomplish one design task may be achieved.

To achieve this goal, some more studies may need to be carried out:

a) Design resource encapsulation: effective encapsulation of various kinds of design resources, make them functional independent, interface standardized reusable entity units with strong configurability.

b) Design resources pool construction: orderly accessing, organization and management of different kinds of distributed design resources.

c) Design process construction and design resources remote call: construct design process by selecting different distributed design resources and drive these resources to run.

To start with, design resources can be encapsulated by SOA technologies into design service modules, and achieve being shared in local network. Then, these modules can be easily expanded to the entire Internet.

\section{ACKNOWLEDGMENT}

This work is supported by the National Natural Science Foundation of China (No. 61502257) and the Research Starting Funds for Imported Talents of Ningxia University (BQD2014020).

\section{REFERENCES}

[1] D. D. Bedworth, M. R. Henderson and P. M. Wolfe. Computerintegrated design and manufacturing. McGraw-Hill, Inc., 1991.

[2] K. Risse, E. Anton , T. Lammering T, et al. "An integrated environment for preliminary aircraft design and optimization." 8th AIAA multidisciplinary design optimization specialist conference, AIAA, Honolulu, HI, 2012.

[3] K. Pimapunsri, S. Tichkiewitch. "Integrated design approach for solving complexity of design problem,” Am. J. Oper. Res., vol.3, 2013.

[4] T. S. Vaquero, J. R. Silva, F. Tonidandel, et al. "itSIMPLE: towards an integrated design system for real planning applications,” Knowl. Eng. Rev., vol. 28, pp. 215-230, 2013.

[5] F. Palacios, M. R. Colonno, A. C. Aranake, et al. "Stanford University Unstructured (SU2): An open-source integrated computational environment for multi-physics simulation and design,” AIAA Paper, vol. 287, 2013.

[6] J. Malins, A. Liapis, J. Kantorovitch , et al. “ Supporting the Early Stages of the Product Design Process: Using an Integrated Collaborative Environment," Proceedings of the E\&PDE 2014 16th International conference on Engineering and Product Design, University of Twente, The Netherlands. 2014.

[7] C. Renzi. “A genetic algorithm-based integrated design environment for the preliminary design and optimization of aeronautical piston engine components”. The International Journal of Advanced Manufacturing Technology,pp. 1-17, 2016.

[8] A. A. G. Requicha and H. B. Voelcker. "Solid modeling: Current status and research directions,” IEEE Comput. Graph., vol. 3, pp. 24-37, 1983.

[9] W. D. Li, W. F. Lu, J. Y. H. Fuh, et al. "Collaborative computer-aided design-research and development status,” Comput. Aided Design, vol. 37, pp. 931-940, 2005.
[10] G. G. Wang. "Definition and review of virtual prototyping,” J. Comput. Inf. Sci. Eng., vol. 2, pp. 232-236, 2002

[11] S. H. Choi, A. M. M. Chan. "A virtual prototyping system for rapid product development,” Comput. Aided Design, vol. 36, pp. 401-412, 2004.

[12] J. Stark. Product lifecycle management, Springer, 2011.

[13] W. M. P. Van der Aalst, A. H. M. ter Hofstede and M. Weske. "Business process management: A survey,” Proceedings of the 1st International Conference on Business Process Management. Eindhoven, Netherlands: Springer Berlin Heidelberg,pp.1-12, 2003.

[14] A. Ciaramella, M. G. C. A. Cimino, B. Lazzerini, et al. "Using BPMN and Tracing for Rapid Business Process Prototyping Environments," Proceedings of the 11th International Conference on Enterprise Information Systems. Milan, Italy, 2009.

[15] W. Van Der Aalst, K. M. Van Hee. Workflow management: models, methods, and systems. MIT press, 2004.

[16] J. Grudin. "Computer-supported cooperative work: History and focus," Computer, vol. 27, pp. 19-26,1994.

[17] W. Reinhard, J. Schweitzer J, G. Völksen, et al. "CSCW tools: concepts and architectures,” Computer, vol. 27, pp. 28-36, 1994.

[18] G. Shuming. "Survey of distributed and collaborative design,” J. Comput Aid. Mol. Des., vol. 16, pp. 149-157, 2004.

[19] M. Saad, M. L. Maher. "Shared understanding in computer-supported collaborative design,” Comput. Aided Design, vol. 28, pp. 183-192, 1996.

[20] M. Philpotts. “An introduction to the concepts, benefits and terminology of product data management,” Ind. Manage. Data Syst., vol. 96, pp. 1117, 1996.

[21] J. X. Gao, H. Aziz , P. G. Maropoulos, et al. "Application of product data management technologies for enterprise integration,” Int. J. Comp. Integ. M., vol.16, pp. 491-500, 2003.

[22] F. Ameri, D. Dutta. "Product lifecycle management: closing the knowledge loops,” Comput. Aided Des. Appl., vol. 2, pp. 577-590, 2005.

[23] M. Alavi, D. E. Leidner. "Review: Knowledge management and knowledge management systems: Conceptual foundations and research issues,” MIS quarterly, pp. 107-136,2001.

[24] H. Xie. Research on the Distributed Integrated Design Environment and Its Key Technologies for Solid Rocket Motor. Hunan: National University of Defense Technology, 2006[In Chinese].

[25] D. E. Coats, J. N. Levine, N. S. Cohen N S, et al. “A Computer Program for the Prediction of Solid Propellant Rocket Motor Performance. Volume 1”. Air Force Rocket Propulsion Lab, 1975.

[26] G. P. Roys. "User's Manual for Solid Propulsion Optimization Code (SPOC). Volume I. Technical Description”. MORTON THIOKOL INC HUNTSVILLE AL HUNTSVILLE DIV, 1981.

[27] L. Acques and J. Roux. "Computer aided preliminary design of solid rocket motors," Proceedings of the 19th Joint Propulsion Conference. Seattle, WA, 1983.

[28] D. L. Gerhardt. "Use of microcomputers for interactive solid rocket motor preliminary design,” Proceedings of THE 20th Joint Propulsion Conference. Cincinnati, OH, 1984.

[29] J. B. Clegern. "Solid rocket motor conceptual design-The development of a design optimization expert system with a hypertext user interface," Joint Propulsion Conference and Exhibit. Monterey ,1993.

[30] J. B. Clegern. "Computer aided solid rocket motor conceptual design and optimization ,” AIAA Paper, pp. 94-0012, 1994.

[31] V. Oh , P. Langdon and J. Sharpe .” Scheme builder: an integrated computer environment for product design,” Computer Aided Conceptual Design. Lancaster International Workshop on Engineering Design. 1994.

[32] A. B. Garcia, R. P. Gocke Jr and N. P. Johnson Jr. "Virtual prototyping: Concept to production”. Defense Systems Management Coll Fort Belvoir VA, 1994.

[33] C. M. Patt and K. J. Richter. "Integrated Product and Process Development (IPPD) Case Examples”. Institute for Defense Analyses Alexandria VA, 1998. 
[34] P. H. Robidoux, S. H. Rousseau, J. R. Stubbe, et al. "Integrated Design and Manufacturing for the Navy FBM Program”. LOCKHEED MARTIN MISSILES AND SPACE CO SUNNYVALE CA, 1996.

[35] P. Landman, R. Mehra, J. M. Rabaey. "An integrated CAD environment for low-power design,” IEEE Des. Test Comput., vol. 13, pp. 72-82, 1996.

[36] T. Hart-Humphrey. "Engineering and Tool Integration.Proceeding of Computer Future in Engineering Design,” Harvey Mudd College,1997.

[37] C. M. Parks, D. A. Koonce, R. P. Judd R P, et al. “An integrated manufacturing systems design environment,” Comput. Ind. Eng., vol. 33, pp. 341-344, 1997.

[38] S. Hasan. "Web-ACSYNT: Conceptual-Level Aircraft Systems Analysis on the Internet," Proceedings of the 1997 World Aviation Congress. AIAA-975509, 1997.

[39] A. Deshmukh, T. Middelkoop, A. Krothapalli, et al. "Multi-agent design architecture for integrated design systems," Proceedings of the 36th AIAA Aerospace Sciences Meeting. America,1998.

[40] K. R. Siarkiewicz. "The Integrated Computational Environment (ICE) for Product Design and Acquisition.” AIR FORCE RESEARCH LAB ROME NY INFORMATION DIRECTORATE, 1999.

[41] D. B. Leake, L. Birnbaum, K. Hammond K, et al. "Integrating diverse information resources in a case-based design environment,” Eng. Appl. Artif. Intel., vol. 12, pp.705-716, 1999.

[42] M. T. Heath, W. A. Dick. "Virtual prototyping of solid propellant rockets,” Comput. Sci. Eng., vol. 2, pp. 21-32, 2000

[43] P. G. Maropoulos, Z. YaoZ, H. D. Bradley, et al. "An integrated design and planning environment for welding -Part 1: Product modeling,” J. Materials Proc. Tech., vol. 107, pp.3-8, 2000.

[44] J. Tang, V. Ogarevic, C. S. Tsai. "An integrated CAE environment for simulation-based durability and reliability design,” Adv. Eng. Softw. , vol. 31, pp. 1-14,2000.

[45] B. Johns, K. Fan, T. Tveten, et al. "Framework for analysis and collaborative engineering (FACE)," Proceedings of the 40th Aerospace Sciences Meeting and Exhibit. America,2002.

[46] B. M. Smith. "IGES: a key to CAD/CAM systems integration,” IEEE Compu. Graph., vol. 3, pp. 78-83, 1983.

[47] G. Moeller. "STandard for the Exchange of Product Model Data (STEP),” Program Manager, vol. 29, pp. 52-56, 2000.

[48] T. K. Peng and A. J. C. Trappey. "CAD-integrated engineering-datamanagement system for spring design,” Robot. Cim.-Int. Manuf., vol. 12, pp. 271-281, 1996.

[49] I. Kim, T. Liebich and T. Maver. "Managing design data in an integrated CAAD environment: a product model approach,” Automat. Constr., vol. 7, pp. 35-53, 1997.

[50] L. Monplaisir. "An integrated CSCW architecture for integrated product/process design and development,” Robot. Cim.-Int. Manuf., vol. 15, pp. 145-153, 1999.

[51] Y. Kim , S. H. Kang , S. H. Lee, et al. “A distributed, open, intelligent product data management system.” Int. J. Comput. Integ. M, vol. 14, pp. 224-235, 2001.

[52] H. J. Cho, J. Hammond, I. D. Tommelein et al. "DePlan: a tool for integrated design management,” Automat. Constr., vol. 13, pp. 313-326, 2004.

[53] A. Schönning, J. Nayfeh, R. Zarda. "An integrated design and optimization environment for industrial large scaled systems,” Res Eng. Des. , vol. 16, pp. 86-95, 2005.

[54] Y. E. Nahm, H. Ishikawa . "An Internet-based integrated product design environment. Part II: its applications to concurrent engineering design,” Int. J. Adv. M. Tech., vol. 27, pp. 431-444,2006.

[55] Y. Takao, K. Tatsuo and S. Akira. "Integrated Design Environment to Support Innovation in Manufacturing,” Fujitsu Sci. Tech. J., vol. 43, pp. 87-96, 2007.

[56] G. Feng, D. Cui, C. Wang, et al. "Integrated data management in complex product collaborative design,” Comput. Ind., vol. 60, pp. 48-63 , 2009.

[57] P. Christiansson, K. Svidt and B. S .Kristian. "Future integrated Design Environment,” J. Info. Tech. Constr., vol.14, pp. 445-460, 2009.
[58] C. S. Hu and C. D. Xu. "Template-Based Integrated Design Environment for Rocket Design,” Adv. Sci. Lett. , vol. 4, pp. 31873192,2011.

[59] M. Haase Tand Nagl. "Application integration within an integrated design environment,” Comput. Chem. Eng., vol. 35, pp. 736-747, 2011.

[60] T. Miyazawa Aand Nagashima. "Construction of Integrated Design Development Environment and Its Deployment on Cloud,” Fujitsu Sci. Tech. J., vol. 48, pp. 394-403,2012.

[61] T. Kvan. “Collaborative design: what is it?,” Automat. Constr., vol. 9, pp. 409-415, 2000.

[62] A. Yassine, D. Braha .” Complex concurrent engineering and the design structure matrix method,” Concurrent Eng., vol. 11, pp.165-176,2003.

[63] R. G. Qiu. "Manufacturing grid: a next generation manufacturing model," IEEE International Conference on Systems, Man and Cybernetics, IEEE, 2004.

[64] C. A. Mattson. "Multidisciplinary design optimization,” Aerospace Am., 2008.

[65] F. Zorriassatine, C. Wykes , R. Parkin, et al. "A survey of virtual prototyping techniques for mechanical product development," Proceedings of the institution of mechanical engineers, Part B: Journal of engineering manufacture, vol. 217, pp. 513-530, 2003.

[66] T. Erl. Service-oriented architecture: a field guide to integrating XML and web services. Prentice Hall PTR, 2004.

[67] C. Baun. Cloud computing: Web-based dynamic IT services. Springer, 2011.

[68] D. Miorandi, S. Sicari, F. De Pellegrini, and I. Chlamtac. "Internet of things: Vision, applications and research challenges,” AD HOC Netw., vol. 10, pp. 1497-1516, 2012.

[69] B. Malone, M. Papay M. "ModelCenter: an integration environment for simulation based design,” Simulation Interoperability Workshop. 1999.

[70] M. Duvall, D. Bartholomew. "PLM: Boeing's dream, airbus' nightmare,” Baseline: The project management center, 2007.

[71] X. Xu. "From cloud computing to cloud manufacturing,” Robot. Cim.Int. Manuf., vol. 28, pp. 75-86, 2012. 